\title{
La agroecología en una encrucijada: entre la institucionalidad y los movimientos sociales ${ }^{1}$
}

\author{
Agroecology at a crossroads: between institutionality and social movements
}

\author{
Omar Felipe Giraldo ${ }^{2}$ \\ Peter Michael Rosset ${ }^{3}$
}

\section{Resumen}

La agroecología está de moda. Es un acontecimiento nuevo con el cual ha aparecido una constelación de oportunidades que pueden aprovechar los movimientos sociales para avanzar en la transformación del sistema alimentario. Sin embargo, también ha emergido el riesgo de que sea cooptada, institucionalizada y despojada de su contenido político. Esta es la disyuntiva que analizamos en el presente artículo en clave de la ecología política: si la agroecología va a terminar siendo parte de la caja de herramientas del sistema agroindustrial para reestructurarse en el contexto de la crisis civilizatoria, o sí, por el contrario, se potenciará como una movilizadora alternativa política para transitar hacia la construcción de las alternativas al desarrollo.

Palabras clave: ecología política, contradicciones del capital, acumulación por desposesión, alternativas al desarrollo.

\begin{abstract}
Agroecology is in fashion. It has burst on the scene as something new that offers a constellation of opportunities that social movements can leverage to push for the transformation of the food system. But the risk of being co-opted, institutionalized and stripped of its political content has also emerged. This is the dilemma we analyze in this article, using a political ecology lens. The question is if agroecology will end up just being part of the toolbox of the agroindustrial food system as it restructures in the context of the civilizational crisis, or, on the contrary, will it be strengthened as a mobilizing political alternative to move us toward the construction of alternatives to development? Keywords: political ecology, contradictions of capital, accumulation by dispossession, alternatives to development.

\footnotetext{
1 Este artículo hace parte del proyecto colectivo "Masificación de la agroecología para los sistemas agroalimentarios sustentables".

Profesor-Investigador. CONACYT-El Colegio de la Frontera Sur (ECOSUR). E-mail: ogiraldo@ecosur.mx Investigador Titular “B”. El Colegio de la Frontera Sur (ECOSUR). E-mail: prosset@ecosur.mx
} 


\section{Introducción}

La agroecología pasó de ser ignorada, menospreciada, y excluida por parte de las grandes instituciones que gobiernan la agricultura en el mundo, a ser reconocida como una de las alternativas posibles para enfrentar las graves crisis ocasionadas por el modelo de la revolución verde. Ello, sin duda, constituye un hecho inédito. Hasta hace muy poco tiempo la institucionalidad encargada de orientar la política agrícola a escala global, había desconocido la "agroecología" tanto en su versión de ciencia, como en su dimensión de práctica y movimiento social (WEZEL et al., 2009). De hecho, no sólo había sido invisibilizada, sino que durante los últimos cuarenta años tuvo que desafiar todas las estructuras de poder en todos los espacios, incluyendo, por supuesto, el conglomerado de instituciones que durante décadas promocionaron la agricultura industrial como la panacea que aliviaría al mundo de los dolores del hambre y la pobreza en el campo. Sin embargo, el contexto cambió sustancialmente en 2014, desde que la agroecología empezó a ser considerada de interés por la "institucionalidad" a partir del Simposio internacional de agroecología para la seguridad alimentaria y nutrición ${ }^{4}$, organizado por la Organización de las Naciones Unidas para la Agricultura y la Alimentación (FAO), en Roma durante septiembre del mismo año.

Se trata, sin duda, de un hecho sin precedentes, que puso a la agroecología en una disyuntiva: ceder ante la cooptación y captura, o aprovechar la apertura de las oportunidades políticas para avanzar en la transformación del modelo agroextractivista hegemónico. Aunque las instituciones no son monolíticas, y existen debates internos, el panorama podría verse como una lucha que tiene como protagonistas a dos bandos. El primero, conformado por las instituciones oficiales de los gobiernos, agencias internacionales y empresarios privados, y el otro, el de los distintos movimientos sociales defienden la agroecología como la única opción viable para transformar radicalmente el sistema agroalimentario imperante.

El terreno de disputa comenzó desde el mismo momento en que la FAO abrió un espacio para la agroecología. De parte de los gobiernos, Francia y Brasil se enfrentaron con Estados Unidos y sus aliados que se oponían a la realización del simposio. La solución a la que llegaron consistió en

$4 \quad$ http://www.fao.org/about/meetings/afns/es/ 
eliminar los contenidos asociados a las políticas públicas; en particular, prohibir la discusión sobre políticas de comercio internacional, transgénicos o términos como "soberanía alimentaria", y ajustar la agenda a los aspectos científicos de la agroecología. Mientras que del lado de la sociedad civil ${ }^{5}$, gracias a los aliados dentro de la misma FAO, se logró ganar espacios en el programa del evento. Al final, las organizaciones campesinas, ONG, y académicos, pudieron emitir sus posiciones críticas con respecto al modelo agroindustrial, aunque su voz fue prácticamente excluida del reporte final (FAO, 2015a). La versión oficial, que emitieron al termino del simposio los ministros de agricultura de Japón, Argelia, Francia, Costa Rica y Brasil, del comisionado de agricultura y desarrollo rural de la Unión Europea, y el Director General de la FAO, es que la agroecología representa una opción más que debe apoyarse, pero combinada con otros enfoques como lo es la intensificación sustentable, la agricultura climáticamente inteligente y los organismos modificados genéticamente (NICHOLLS, 2014).

Como respuesta a esta posición que reduce la agroecología a un conjunto de ecotecnias que deben integrarse a la caja de herramientas del modelo de producción alimentaria industrial, los movimientos sociales ${ }^{6}$ se manifestaron durante el Foro Internacional de Agroecología realizado en Nyéléni, Mali, en febrero de 2015. ${ }^{7}$ Fue la primera ocasión en que se reunieron no sólo campesinos, sino representantes de comunidades indígenas, pastores, pescadores artesanales, pobladores urbanos y consumidores en torno a la agroecología - algo que ya había ocurrido para la reforma agraria y la soberanía alimentaria (MARTÍNEZ-TORRES y ROSSET, 2014; ROSSET, 2013). La declaratoria (LVC, 2015a) constituye un documento fundamental ya que por primera vez agrupó diversas visiones para definir, mediante el diálogo de saberes, lo que es la agroecología para los movimientos sociales. En el documento aseguraron que la agroecología está en peligro de

\footnotetext{
5 Sociedad Científica Latinoamericana de Agroecología (SOCLA), El Mecanismo de Sociedad Civil (CSM) de la FAO, el Comité Internacional de Planificación por la Soberanía Alimentaria (CIP), La Vía Campesina

6 Coordinación Nacional de Organizaciones Campesinas de Malí (CNOP Mali); La Vía Campesina, Movimiento Agroecológico de América Latina y el Caribe (MAELA), Réseau des organizaciones Campesinas y de Productores de l'Afrique de l'Ouest (ROPPA), Foro Mundial de Pescadores y Trabajadores de la Pesca (WFF), Foro Mundial de Pueblos Pescadores (WFFP), Alianza Mundial de los Pueblos Indígenas Móviles (WAMIP), y Más y Mejor (MaB).

7 https://viacampesina.org/es/index.php/temas-principales-mainmenu-27/agricultura-campesina-sosteniblemainmenu-42/2336-la-via-campesina-y-sus-aliados-organizan-el-foro-internacional-de-agroecologia-orientado-a-lasoberania-alimentaria
} 
cooptación pues el sistema alimentario industrial busca maquillarse mediante un discurso verde, al tiempo que rechazaron equiparar la agroecología con la producción industrial de monocultivos de alimentos "orgánicos", y los otros enfoques que vienen promoviendo la misma FAO. Los delegados que participaron en el foro, se manifestaron en favor de una agroecología eminentemente política y popular, que busca desafiar y transformar las estructuras de poder en la sociedad, lo que en otras palabras quiere decir: "poner en manos de los pueblos que alimentan el mundo el control de las semillas, la biodiversidad, la tierra y los territorios, el agua, los saberes, la cultura y los bienes comunes" (LVC, 2015a).

Asistimos a una disputa entre dos formas radicalmente distintas de concebir la agroecología, una, estrechamente técnica, cientificista e institucional, y la otra, la de los pueblos, profundamente política que aboga por la justicia distributiva y el replanteamiento total del sistema alimentario. Se trata de un debate que encontró como escenario a la FAO, y que continuó en las conferencias regionales sobre agroecología que siguieron al simposio de Roma, y que se llevaron a cabo durante el 2015 en Brasilia, para América Latina y el Caribe; en Dakar, para África subsahariana; y en Bangkok para Asia y el Pacífico. De los tres seminarios, Brasilia fue el espacio más favorable para los movimientos sociales, en la medida en que no sólo se logró dominar el discurso, sino incluir en el documento final - acordado junto a los representantes de la FAO, gobiernos, académicos, la CELAC (Comunidad de Estados de América Latina y el Caribe) y el REAF (la oficina de la agricultura familiar del MERCOSUR) -, la mayor parte de sus posturas, con la notable excepción de críticas explícitas al agronegocio y los transgénicos. En las conferencias de Dakar y Bangkok, el contexto fue más conflictivo, en la medida en que se percibió más el intento de hacer de la agroecología un sinónimo de la intensificación ecológica y la agricultura climáticamente inteligente y la respuesta de parte de los movimientos sociales de rechazar esos intentos de cooptación (ROGÉ, NICHOLLS y ALTIERI, 2015; NICHOLLS, 2015).

Es muy evidente cómo en el transcurso de unos cuantos meses, la agroecología fue reconocida, por primera vez, por la institucionalidad que gobierna la política de agricultura en el mundo, y la forma en que se fue configurando un campo en conflicto con dos bandos en disputa que luchan por su significación. Hoy la agroecología tiene su propia dependencia en las oficinas de la FAO en Roma, y los ministerios de agricultura de los países empiezan a conformar políticas 
públicas sobre "agroecología", y las universidades nuevos programas de estudio. Lo anterior no es un tema menor. En poco tiempo la agroecología empezará a tener presupuestos específicos, las grandes multinacionales y fundaciones empezarán a invertir en la agroecología, y nuevas ONG y otras organizaciones oportunistas, que nunca antes habían defendido la agroecología, empezarán a hacerse voceras y beneficiarse de las oportunidades económicas y políticas que emergen de este nuevo contexto internacional.

En este artículo, interpretamos el surgimiento de la agroecología para la agenda de la FAO, desde la óptica de la primera y la segunda contradicción del capital, y desde la apropiación por el discurso del desarrollo. Lo que nos interesa analizar es cómo y porqué la agroecología empieza a ser de interés en la geopolítica global como intento del agrocapitalismo de escapar a sus propias contradicciones, y la manera en que los movimientos sociales podrían salir fortalecidos, siempre y cuando defiendan la agroecología como una alternativa al desarrollo y un componente imprescindible para las transiciones hacia un mundo más allá del capitalismo.

\section{Los ensayos por apropiarse de la agroecología y las contradicciones del capital}

En esta primera sección queremos proponer que tanto la primera como la segunda contradicción del capital, ofrecen un excelente marco de lectura para entender la nueva coyuntura internacional para la agroecología. En términos generales, la primera contradicción nos ayuda a comprender las razones por las cuales el capital intenta incorporar la agricultura campesina, sus territorios y sus prácticas agroecológicas a los circuitos globales de acumulación de capital; mientras que la segunda, nos ofrece una explicación de cómo el agroextractivismo pretende enfrentar su tendencia a incrementar sus costos y a reducir su productividad.

La primera contradicción describe la tendencia del capitalismo a entrar recurrentemente en crisis, debido a que la capacidad productiva tiende a aumentar de una manera mucho más rápida que la demanda efectiva. En otras palabras, el sistema es proclive a producir más de lo que se puede consumir (O’CONNOR, 2001) y, en consecuencia, a entrar en una sobreproducción de mercancías, como lo describió Marx en su explicación de la caída de las tasas de ganancia (1946: 213 y ss.). 
Para salir de esta crisis, el capitalismo necesita trasladar el capital sobrante a otros espacios geográficos, para poner allí en movimiento un nuevo proceso dinámico de acumulación, y de ese modo la crisis pueda solucionarse durante algunos años más (HARVEY, 2005).

El problema, es que con el tiempo, la hipercompetencia internacional producida por la expansión geográfica del capitalismo ${ }^{8}$, hace que se termine por generar nuevamente excedentes que no pueden ser absorbidos por el sistema. Es lo que justamente parece estar ocurriendo a escala global, pues existe evidencia de que por lo menos desde el año 1973, el capitalismo padece de una enfermedad crónica de sobreacumulación, de la que hasta hoy no ha podido salir (BRENNER, 1999). La crisis económica, se refleja en excedentes de capital que permanecen ociosos, sin que existan posibilidades de encontrar alternativas de inversión para la obtención de ganancias atractivas. Aunque la solución paliativa que sirvió como huida de la crisis derivada de la sobreoferta de mercancías fue la financiarización ${ }^{9}$ y sus burbujas especulativas, el remedio de fondo fue poner en operación una estrategia de expoliación respaldada y promocionada por los Estados nacionales mediante políticas neoliberales privatizadoras, para transferir activos públicos o comunes a empresas privadas, para luego insertarlos a los flujos privados de acumulación de capital. Este proceso, que recuerda la acumulación originaria descrita por Marx, y que ha sido rebautizada como “acumulación por desposesión” por el geógrafo David Harvey (2005), no es más que una operación desvergonzada de pillaje que busca apropiarse de recursos sin remunerar a los pueblos a quienes les pertenece.

Robert Brenner (2009, p.14) describe así la caída en las tasas de rendimiento en inversión internacional como producto de la competencia a escala global: "Lo que ha ocurrido es que nuevos poderes industriales fueron ingresando, uno tras otro, al mercado mundial: Alemania y Japón, los nuevos países industrializados del sureste asiático y, finalmente, el Leviatán Chino. Esas economías de desarrollo tardío producían los mismos bienes que ya producían las economías más tempranamente desarrolladas, pero más baratos. El resultado ha sido un exceso de oferta con relación a la demanda en una industria tras otra, y eso ha implicado precios a la baja y, por lo mismo, beneficios bajos. Las empresas que han sufrido reducción de beneficios, además, no han abandonado dócilmente sus industrias. Han intentado conservar su lugar recurriendo a la capacidad de innovación, aumentando la inversión en nuevas tecnologías. Huelga decir que eso no ha hecho más que empeorar la sobrecapacidad".

$9 \quad$ Como explica James O'Connor (2001, p. 288) gracias a la financiarización "el capital monetario abandona el "circuito general del capital", es decir, el largo y tedioso proceso de rentar espacio para una fábrica, comprar maquinaria y materias primas, rentar tierra, encontrar fuerza de trabajo adecuada, organizar y poner en práctica la producción y comercializar mercancías, y se abre camino hacia empresas especulativas de todas clases. El capital monetario basado en la expansión del crédito, o el dinero que no puede encontrar salida en bienes y servicios verdaderos, se brinca, por decirlo así, a la sociedad, y busca expandirse de manera más fácil por medio de la compra de tierras, de los mercados bursátiles, los mercados de bonos y otros mercados financieros".

Guaju, Matinhos, v.2, n.1, p. 14-37, jan./jun. 2016 
No cabe duda de que en el marco de la crisis - que se agudizó a partir del desplome de la burbuja financiera del periodo comprendido entre los años 2007 y 2009 -, el capital especulativo necesitó buscar nuevas formas de acumulación y nuevas formas de especulación. Y es aquí donde encontramos la primera explicación del renovado interés de la institucionalidad por promover y respaldar la agroecología. El capital que durante años logró refugiarse en los metafísicos mercados financieros, empezó a buscar, por todos los medios, la manera de apropiarse de las riquezas naturales de las que depende toda actividad económica. Ya es conocido el acaparamiento de tierras, la fiebre de inversión en monocultivos agrícolas y forestales, petróleo, hidrocarburos no convencionales y minerales en los países del Sur global (BORRAS et al, 2011). Lo que ahora empieza hacerse evidente, es que el capital también busca mercantilizar las semillas y la agrobiodiversidad; despojar los saberes agroecológicos de los campesinos y comunidades indígenas; insertar mayor diversidad agrícola a los mercados de alimentos, la industria cosmética, y farmacológica; incrementar los beneficios derivados de los bonos de carbono y la conservación neoliberal mediante arreglos agroforestales; y lucrar por la ampliación de los mercados de productos orgánicos industriales, que pronto serán renombrados como agroecológicos en las grandes superficies. El objetivo es transferir los bienes comunes de los pueblos en derechos de propiedad privada, y escindir a las comunidades de sus condiciones materiales y simbólicas de existencia, haciendo imposible a los pueblos vivir por fuera de las redes del mercado (LVC, 2016; MARTÍNEZ-TORRES Y ROSSET, 2016; 2012; ROSSET, 2009).

Si la agroecología agrupa el conjunto de prácticas construidas por los pueblos en sus procesos milenarios de transformación ecosistémica, la crisis del capitalismo a escala global, es la ocasión precisa para insertar todas aquellas prácticas a los circuitos globales de acumulación de capital. Hay que recordar que no hay posibilidad de que exista acumulación sin un proceso incesante de expansión geográfica (HARVEY, 2003), lo que significa incluir todos los territorios que no se encontraban ceñidos por completo a las lógicas de valorización del capital, a los flujos de la globalización neoliberal (COMPOSTO Y NAVARRO, 2014). La idea no es mantener determinados territorios al margen del crecimiento capitalista, sino hacerlos parte del sistema. No excluir formas de producción no capitalistas, sino al contrario: incluirlas, teniéndolas bajo la cuidadosa mirada del poder. 
No hay mejor forma para aplacar las demandas, y la defensa que hacen los movimientos sociales de la agroecología como una de las alternativas para superar el capitalismo hegemónico, que capturarla, coaptarla, y vaciarla de todo contenido antisistema. Para ello se requiere, insistimos, no marginar, sino mantener la agroecología en ciertas coordenadas de control, haciendo a los campesinos, pastoralistas, agricultores familiares, y pescadores funcionales a la acumulación, articulándolos con las economías empresariales. Finalmente, estas poblaciones cultivan, pastorean, y pescan, en áreas que no son de interés directo para el agronegocio, por lo menos no a la manera clásica del despojo usurpador. Y en tal sentido es más práctico desterritorializarlos sin desplazarlos de sus tierras, de modo que sean útiles para la obtención de rentas extraordinarias (GIRALDO, 2015).

Porque como dice Armando Bartra (2016; 2013), la acumulación por desposesión en solo la premisa fundante requerida para acumular. No es la acumulación por sí misma. Por eso la clave para entender el proceso completo, es la manera como se valoriza lo expropiado a través del análisis de las rentas. Con el despojo de las prácticas, saberes, semillas, el agua, la tierra, el aire, dice Bartra, se pone a disposición del capital recursos que el capital no puede producir por sí mismo. Sin embargo, lo que empieza con el despojo, culmina con la valorización de lo despojado, valorización que no ocurre en función de la inversión productiva, sino de la propiedad monopolista de bienes escasos, con calidades diferenciadas, con cuya propiedad excluyente se puede especular. Bartra sostiene, además, que con la expropiación, no sólo existen ganancias, sino rentas, es decir, ingresos extraordinarios de carácter especulativo, que provienen del fondo común del capital global -que a su vez no puede originarse de otro lado sino del excedente producido por el trabajo-, los cuales son apropiados por los primero despojadores y luego especuladores.

La agricultura es un sector privilegiado para esta forma de acumular, porque buena parte de lo que genera son rentas diferenciales que vienen de la propiedad territorial (BARTRA, 2013). Particularmente, la agroecología, puede ser un área propicia para aumentar las rentas del agronegocio, siempre y cuando se encadene a los mercados internacionales. Lo anterior puede comprenderse si aceptamos que la agroecología continuará siendo un activo del que no puede soslayarse el trabajo y saberes de los pequeños agricultores del Sur global. Por eso, aunque algunos campesinos salen sobrando y estén siendo expulsados de sus territorios, muchos otros son más 
útiles si se logra apropiarse de su plusvalía y de las rentas de forma indirecta. Es decir, es poco viable que los grandes capitales intenten adueñarse de tierras poco fértiles y con infraestructura precaria, por los costos en la inversión que ello implicaría. En cambio, resulta mucho más útil poner a disposición los predios en las que millones de personas cultivan -la misma declaración de Nyéléni, sostiene que los pequeños agricultores sumados son los mayores inversionistas del mundo-, para usufructuarlos indirectamente, y ello se logra ampliando el espectro de productividades para que el agrocapitalismo se apropie de la renta diferencial ${ }^{10}$. Como el problema de la crisis crónica, consiste en que los capitales individuales no encuentran opciones rentables para acumular, resulta lógico que la agroecología incluida subordinadamente dentro de la geopolítica mundial ayude a generar rentas extraordinarias, además de que aumenta el poder del gran capital sobre territorios lejanos y dispersos que de otra forma sería muy difícil controlar.

La acumulación por desposesión es una estrategia que no se da el lujo de omitir ningún rincón, ni área económica que eventualmente pueda aprovecharse para la valorización del capital. Y si aún el $70 \%$ de la producción alimentaria mundial se encuentra en manos de pequeños agricultores (ETC group, 2009), muchos de ellos agroecológicos, sería un desperdicio excluir su actividad de las actividades capitalistas. Pero dado que es prácticamente imposible transformar todas las tierras del orbe en monocultivos intensivos en capital, la mercantilización de la agroecología puede llegar a ser un buen dispositivo para controlar tierras que apuntan a ser fuente de rentas cuantiosas como lo muestran las expectativas en torno al crecimiento demográfico y económico para el año 2050 (FAO,

10 La renta diferencial ha sido utilizada para explicar la supervivencia del campesinado. En pocas palabras la explicación consiste en que el capitalismo necesita de esta población, no sólo porque es proveedora de mano de obra estacional y barata para la agricultura comercial, sino porque en la agricultura -así como todas las demás actividades que dependen directamente de bases naturales- se presenta el fenómeno de la renta diferencial. Es ampliamente debatido por la disciplina económica que la actividad agrícola, a diferencia de la industria, se basa en la tierra: un bien natural escaso y con diferentes calidades de fertilidad y ubicación. Esa característica hace que las mejores tierras sean monopolizadas por capitalistas individuales, de modo que en una misma actividad económica coexisten productividades diferentes. Dado que en el mercado se requiere que aún en las peores tierras se obtenga una ganancia o por lo menos se recupere el costo, el precio de los productos agrícolas no giran en torno a los costos de producción medios -como ocurre en la industria- sino con base en los costos de las tierras con menos fertilidad y con peor ubicación con respecto al mercado. Esta manera de fijación del precio, hace que la sociedad tenga que sufragar un sobrecosto, un pago de más, por los productos agrícolas, el cual se reparte entre los capitalistas que acaparan las mejores tierras una vez han recuperado la inversión y obtenido una ganancia media. De una manera muy sintética ése el fundamento de la renta territorial, que aclara porqué el capitalismo construye una estructura agraria compuesta por unidades capitalistas y campesinas, pero que al mismo tiempo necesita de campesinos ampliamente integrados a los mercados. Para un mayor detalle de la exposición del fenómeno véase Bartra (2006).

Guaju, Matinhos, v.2, n.1, p. 14-37, jan./jun. 2016 
2015b), los pronósticos de escasez de agua (FAO y WWF, 2015) y las tendencias de erosión de la biodiversidad (LOH, 2000; CROWTHER et al. 2015; MEA, 2015). No puede perderse de vista que las rentas dependen de la escasez de aquello que se quiere monopolizar, por lo que las predicciones sobre la escasez creciente que se avecina, son una excelente noticia para las aspiraciones del capitalismo especulador que está buscando evadir la tendencia decreciente de ganancias y la volatilidad en los mercados bursátiles (BARTRA, 2016).

La segunda explicación del reciente interés de la institucionalidad por incluir la agroecología en su agenda, está en lo que el marxismo conoce como la segunda contradicción del capital. Esta contradicción derivada de un comentario que Marx hiciera sobre el contrasentido de la tecnología en la agricultura ${ }^{11}$, da cuenta de cómo el tipo de tecnologías empleadas por el capitalismo degradan las condiciones naturales de producción y ponen en riesgo sus propias utilidades (O'CONNOR, 2001). En el agronegocio la búsqueda constante de producir siempre más, aumentar los rendimientos, y mejorar la eficiencia, ha originado, paradójicamente, el estancamiento de los rendimientos (RAY, et al. 2012) y un declive en las primeras zonas de la revolución verde (PINGALI et al., 1997); además de erosión, compactación, salinización y estilización de los suelos (KOTSCHI, 2013); pérdida de biodiversidad funcional para los agroecosistemas; resistencia a plaguicidas; y disminución de la efectividad de fertilizantes de síntesis química. Las pretensiones de hiperproductividad del agronegocio han acabado por socavar las fuentes del proceso productivo, conllevando a una crisis del sistema agroalimentario (LEFF, 1998).

Es cada vez más evidente que el agrocapitalismo es autodestructivo, pues no puede abstenerse de fracturar sus propias condiciones de producción, lo que quiere decir simplificar y sobreexplotar los ecosistemas, erosionar la fertilidad de los suelos, y contaminar las aguas y emitir a la atmósfera gases con efecto invernadero (LIN et al., 2011). En términos económicos lo anterior significa una subproducción del capital, es decir, un decrecimiento en las utilidades acompañado

\footnotetext{
11 “...todo progreso, realizado en la agricultura capitalista, no es solamente un progreso en el arte de esquilmar al obrero, sino también en el arte de esquilmar la tierra, y cada paso que se da en la intensificación de su fertilidad dentro de un periodo de tiempo determinado, es a la vez un paso dado en el agotamiento de las fuentes perennes que alimentan dicha fertilidad... Por tanto, la producción capitalista solo sabe desarrollar la técnica y la combinación del proceso social de producción socavando al mismo tiempo las dos fuentes originales de toda riqueza: la tierra y el hombre" (MARX, 1946, p. 423-424).
} 
por un incremento en los costos de producción. Ejemplo de ello es el hecho de que cada vez se tengan que usar mayores dosis de fertilizantes y pesticidas para lograr los mismos rendimientos que en el pasado. Sin embargo, aunque la devastación ambiental es imposible que sea detenida por medio de arreglos técnicos dentro del mismo sistema, la crisis es aprovechada por el capital agrícola para reestructurarse y hacer toda clase de transformaciones con el ánimo de bajar los costos de producción e intentar aumentar la productividad.

Según dice James O’Connor (2001), el capitalismo no solo está expuesto a las crisis, sino que depende de ellas para reestructurarse. Pues bien, hoy todo parece indicar que el capitalismo agrícola, con la ayuda de los Estados y las organizaciones multilaterales, está en un proceso de transformaciones para resolver la crisis a su favor. Esos cambios incluyen la agroecología, cuyo contenido se vislumbra como una de las opciones técnicas que pueden hacer parte del paquete tecnológico para restablecer las condiciones de producción. Por lo menos esa es una de las conclusiones que pueden deducirse de los mensajes claves de la convocatoria al Simposio Internacional "La función de las biotecnologías agrícolas en los sistemas alimentarios sostenibles y la nutrición" celebrado en Roma durante febrero de 2016:

La FAO cree que con el fin de superar los efectos del cambio climático y otros desafíos que impiden a los países miembros alcanzar sistemas alimentarios y nutrición sostenibles, tenemos que considerar todas las soluciones posibles, incluyendo la agroecología y las biotecnologías.

Según la FAO, la agroecología es una opción más que puede compatibilizarse con las opciones biotecnológicas disponibles, que incluyen los transgénicos, pero también otras manipulaciones genéticas que sirven para incrementar la productividad:

Por ejemplo las biotecnologías y sus productos pueden utilizarse en los sistemas de producción, basados en principios agroecológicos, a fin de aumentar la productividad y garantizar al mismo tiempo la sostenibilidad, la conservación de los recursos genéticos y la utilización de los conocimientos tradicionales (FAO, 2016b, p. 3-4) . 
El orden del discurso va haciendo evidente el interés del capital, y el respaldo de la institucionalidad que orienta la política agraria global, de hacer hibridaciones entre las biotecnologías agrícolas y veterinarias con la agroecología, para recuperar el sustento natural degradado por la intervención contranatura realizada por el agroextractivismo. Con seguridad esta preocupación de hacer adecuaciones técnicas al sistema responde a una honesta preocupación de la agricultura industrial por haber deteriorado sus posibilidades de reproducción. Por eso, además de la agroecología, hay una nueva promoción de algunos paquetes tecnológicos que intentan pintar el agronegocio de verde como lo es la agricultura climáticamente inteligente, la intensificación sustentable, la agricultura orgánica con base en insumos comerciales, transgénicos resistentes a las sequías o la agricultura de precisión.

Pero la crisis originada por la tendencia del capital a negarse a sí mismo y devastar el sustrato natural del que depende, también es un buen momento para ampliar y crear nuevas fuentes de negocios, como lo que en el futuro podría convertirse "la industria de insumos agroecológicos", los monocultivos orgánicos para nichos de exportación, o la internalización de los costos de la degradación ambiental para obtener ingresos con la venta de bonos de carbono (LVC, 2011; LEFF, 2004), el ecoturismo y el biocomercio. La crisis también es aprovechada para flexibilizar y disminuir los costos de fuerza de trabajo gracias a las alianzas con pequeños agricultores mediante figuras como la agricultura por contrato, y la inclusión de las familias que practican la agroecología a la lógica empresarial para abastecer los mercados del capital.

En resumidas cuentas la devastación ambiental es una excusa para abrir nuevos instrumentos de planeación para el capital a gran escala para reestructurar la utilidad, disminuyendo los costos, creando nuevos bienes de consumo, e intentando restablecer las condiciones naturales de la producción (O’CONNOR, 2001). Como Foucault (2010) observó, no puede decirse cualquier cosa en cualquier momento; es necesario que surjan ciertos acontecimientos y cambios para que un tema adquiera el estatuto para ser discutido. Las transformaciones ocurridas para que la agroecología pudiera hacer parte del discurso de la FAO, responden, en gran medida, a la agudización de la estrategia de la acumulación por desposesión de los últimos años, y los intentos del agrocapitalismo de reorganizarse en el contexto de la crisis ocasionada por sus propias contradicciones. 


\section{Los proyectos del desarrollo y la colonización de la agroecología}

La eventual cooptación de la agroecología también puede verse como una muy sofisticada manera de apaciguar las revoluciones agroecológicas que han venido creciendo en diversas latitudes (KHADSE et al. 2016; LVC, 2015b; ROSSET et al., 2011; ALTIERI y TOLEDO, 2011; HOLTGIMENEZ; 2008;), y que fácilmente pueden corromperse mediante las clásicas estrategias del desarrollo. Según ha sido descrito por sus más agudos críticos (ILLICH, 2006; ESCOBAR, 2007; ESTEVA, 2011), el desarrollo es un sofisticado dispositivo de poder que primero atribuye necesidades a una población para luego ofrecer satisfacerlas mediante la ciencia, la tecnología y la política. Crea primero anormalidades, para establecer luego instancias de control sobre lo anormalizado (FOUCAULT, 2000). La pobreza, el hambre, y la malnutrición, son anomalías que han sido definidas mediante una fina estrategia que primero decreta el defecto, la enfermedad, para luego instaurar su cura por medio de una planificada intervención institucional.

La pobreza que debe ser socorrida con la benevolente bendición de la ayuda institucional, define los modos de vida aceptables, y determina como defecto a ser corregido, cualquier manera de existencia que no se ajuste a los imaginarios del progreso, la modernización, y el consumo. De esa manera, la vida de la gente se define de acuerdo a lo que carece: falta de ingreso suficiente, falta de educación moderna, persistencia de tecnología atrasada. Y si el problema desde el comienzo señala que se trata de un problema que tiene terapia, el desarrollo interviene llevando bienes y servicios a una población objetivo. Las personas víctimas del engranaje institucional del desarrollo, terminan siendo absorbidas por la economía monetaria al tiempo que les es negada cualquier forma de reproducción de sus vidas que no esté acoplada por completo a las dinámicas de los mercados (ILLICH, 1996).

De acuerdo a la racionalidad económica que subyace al discurso, el campesinado ha sido representado en términos de falta de rentabilidad, eficiencia y productividad, y necesitado de capital y tecnología. Así, mediante estructurados programas de desarrollo rural a lo largo y ancho del mundo, se fueron creando clientes para las multinacionales productoras de insumos, estimulándolos a especializarse en monocultivos y razas comerciales, y a cultivar y criar animales haciendo uso de 
agroquímicos y biotecnologías veterinarias. El objetivo, no fue otro que llevar revolución verde a la mayor parte de los campesinos del mundo, y ampliar la gama de clientes generando la expectativa de volverlos pequeños empresarios (ESCOBAR, 2007). De alguna manera la idea era que la gente dejara de ser lo que hasta entonces habían sido, impedirles subsistir como comunidades territorializadas, acabar con sus ámbitos comunitarios, y embarcarlas en el tren del capitalismo a escala global (ESCOBAR, 2014). La crisis ambiental originada en buena medida por el enorme andamiaje del desarrollo rural, está obligando a cambiar algunos de sus supuestos. Aunque la anormalidad sigue siendo la misma -pobreza, hambre, subnutrición, o ausencia de educación-, el remedio está siendo aderezado con la inclusión de la agroecología, con lo cual no solo se lograría deslegitimar el enorme rechazo de la revolución verde por parte de los movimientos sociales, sino someter los saberes de los pueblos imponiendo dependencias al sistema que desde ahora intentará proveer servicios agroecológicos a través de los Estados, ONG oportunistas, transnacionales, y proyectos de fundaciones y organizaciones internacionales.

La maquinaria del desarrollo pretende continuar ofreciendo solución a una necesidad que los proyectos prometen satisfacer (ILLICH, 1996). Así las formas de vida tradicionales de los pequeños agricultores, pueblos indígenas, pastores nómadas, y pescadores seguirán siendo enunciadas en términos de pobreza, subdesarrollo y atraso, pero ahora se prometerá su salvación de la mano mesiánica de los proyectos agroecológicos de los gobiernos. El objetivo será continuar creando clientes de los proyectos, volviendo a los pobladores rurales en objetivo de los servicios profesionales agroecológicos. Por supuesto, como se evidencia con el amalgamiento con la biotecnología, la institucionalidad no está dispuesta a renunciar al saber experto que se transmite de arriba abajo, generando invalideces y haciendo a la gente consumidora de una nueva forma de servicio incapacitante (ESTEVA, PRAKASH y STUCHUL, 2005).

No puede olvidarse que las tecnologías del capitalismo agrícola funcionan de tal forma que impiden a sus usuarios tener acceso a su diseño y elaboración, lo cual es una poderosa manera de impedir ciertas formas de auto-organización social (HARVEY, 2004). Es lo que justamente la agroecología había desafiado mediante metodologías como campesino a campesino (VÁSQUEZ y RIVAS, 2006; HOLT-GIMENEZ, 2008; MACHÍN et. al., 2010;), en donde los agricultores son experimentadores que difunden sus saberes mediante el diálogo directo y la pedagogía del ejemplo. 
Pero con la muy probable invasión de los proyectos agroecológicos institucionalizados por las políticas públicas se colonizará este tipo de procesos autonómicos, haciendo a la gente vulnerable de la dictadura de los expertos. El desarrollo en últimas, está conformado de tal forma que aumenta el margen de control por instituciones externas, las cuales intentan redimir y enseñar a quien no sabe, llevando de la mano, como niños necesitados de dirección adulta, a las comunidades a través de una rigurosa gestión de su tiempo y sus acciones cotidianas.

El desarrollo operado por un sinfín de proyectos ha vuelto a la gente blanco del saber experto, despojando a los pueblos de su capacidad creativa, castrando la imaginación social e imponiendo conocimientos, formas de producir y consumir obligatorios (ILLICH, 2006). Valdrá la pena tener presente que la colonización industrial de la agroecología se hará por el lado de la sustitución de insumos - biopesticidas, biosólidos y otros productos comerciales -, pero ante todo por una lógica, cuya racionalidad ordena las formas de existencia de acuerdo a la demanda de los mercados y la motivación del lucro (POLANYI, 2003), la producción serial creciendo al ritmo de la acumulación incesante del capital, y la uniformización, que condena al emparejamiento de las tareas y actividades. Esa es justamente la tarea que durante décadas han desempeñado los programas y proyectos del desarrollo, y nada nos dice que si la agroecología es apropiada por los ministerios de agricultura y se incluye a los planes nacionales de los gobiernos neoliberales o progresistas, algo de eso vaya a cambiar.

Así, aunque las prácticas estén inscritas de algún modo a las potencialidades ecológicas y condiciones naturales de los lugares, los agentes externos terminarán por controlar los sistemas de producción, distribución y consumo, y las comunidades acabarán por quedar atadas a la intermediación de las cadenas industriales globales, volverse dependientes del consumo de productos y servicios, hacerse vulnerables a los vaivenes de la globalización económica, y terminar subordinadas a los mandatos del mercado.

Parece que el capitalismo verde ha descubierto la agroecología para legitimar una geopolítica agrícola dual, en la que por un lado se busca crear una agroindustria reestructurada con un renovado discurso de sustentabilidad e inversión responsable, mientras que por el otro, una agricultura campesina de base agroecológica ligada a la economía empresarial mediante acuerdos de asociación con empresarios agroindustriales, agricultura por contrato y otras formas de 
articulación a las cadenas comerciales. No hay duda de que el discurso verde es un potente medio de legitimación, frente a la evidencia, en todos los frentes, que las tecnologías del capitalismo agrícola están llevando al capital a destruir sus propias fuentes de sostenibilidad económica. Tal vez a lo que estamos asistiendo es al inicio de una nueva etapa de la revolución verde, que está mudando su ropaje para disfrazarse ahora sí “de verde”, y de esa forma legitimarse con un discurso agroecológico de inclusión social, alimentación saludable, y protección de la madre tierra.

No podemos perder de vista, que uno de los principios de las democracias liberales es que todas las expresiones de la sociedad participen del poder político. De hecho, el pluralismo participativo es una manera muy sutil de ejercicio del poder (GIRALDO, 2014) para inhabilitar discursos contestatarios y apaciguar la movilización social en contra de la agricultura industrial, al mismo tiempo que la legitima, pues se hace menos evidente su poder hegemónico. En ese escenario la intervención del desarrollo resulta fundamental ya que cumple la útil función de incorporar la agroecología a la planificación internacional del capitalismo globalizado.

\section{La agroecología en el marco de las alternativas al desarrollo}

Ha quedado claro se ha abierto la lucha entre dos bandos, y el resultado final dependerá de la correlación de fuerzas en los escenarios donde se libra la disputa, pero también de la capacidad de los movimientos sociales de mantenerse distanciados de los postulados del desarrollo. Opinamos que es un momento ideal para incrementar el sentido crítico de la agroecología hacia la racionalidad económica y los imaginarios del progreso, y defenderla como un componente sustancial de las alternativas para enfrentar la crisis civilizatoria. El cuestionamiento a los nuevos modelos de simulación y cooptación agroecológica, solo podrá ser completo si las visiones y estrategias están en la vía de lo que en Latinoamérica se denomina como el buen vivir, lo que significa resistir al control de las instituciones externas, y ejercer una agroecología autónoma, en donde se asuma la responsabilidad de hacerse cargo de los problemas por los mismos involucrados.

También implica rechazar todo intento de imposición de recetarios técnicos y metodológicos de aplicación universal, y aumentar la fuerza de los procesos alternativos al desarrollo que la misma 
agroecología viene construyendo, como lo es la creatividad colectiva, la invención social y la diversificación en los modos de producir, consumir, ser y existir. En otras palabras, y parafraseando a los zapatistas, rehusarse aquel mundo hecho del único mundo del desarrollo, que despoja a los individuos de su capacidad creativa, y revitalizar, en cambio, los múltiples mundos que aprenden unos de otros, como muy bien lo hacen metodologías agroecológicas, a las cuales les estorban la lógica de los proyectos y los programas clientelares de los gobiernos. La manera de habitar fundada en la creatividad cultural y el ordenamiento ecosistémico específico a cada lugar que fomenta la auténtica agroecología, hace todo lo contrario de lo que hace el engranaje del desarrollo: mejorar los lazos comunitarios, ampliar la ayuda mutua, aumentar el control de las personas sobre sus propias vidas, y poner todas las herramientas bajo el poder de los agricultores.

Defender la agroecología del despojo institucional, implica también impugnar el economicismo que reduce la agroecología a la productividad, rendimientos, y la competitividad del neoliberalismo económico y científico (GIRALDO, 2013), y ampliar el sentido crítico para reposicionarla como formas de morar la Tierra que están atadas a las cosmovisiones de los pueblos, a sus formas de comprensión simbólicas, sus relaciones de reciprocidad, y sus maneras de existencia y re-existencia (PORTO-GONÇALVEZ, 2009). Porque mucho más que un modo de producir, la agroecología en una forma de ser, de comprender el mundo, de habitarlo, de sentirlo. Es una manera de relación social distinta al capitalismo ${ }^{12}$, que incentiva la recuperación e intercambio de saberes locales, la creación común de nuevos conocimientos en el mismo lugar donde ocurren los problemas, y la transformación ecosistémica conforme a las condiciones de regeneración de la vida (DA SILVA, 2014).

Pero además de la descolonización del saber la resistencia a los dispositivos despojadores y rentistas en los que ha devenido el capitalismo global en nuestros días, requiere recuperar el sentido de lo común. Y esto implica seguir rechazando todos los modelos del agronegocio, el latifundio y la

\footnotetext{
12 Como lo expresa la Vía Campesina (2015b): "El proyecto de La Vía Campesina es un “proyecto de vida,” para un campo con campesinas y campesinos, de comunidades rurales con familias, de territorios con árboles y bosques, montañas, lagos, ríos y costas, y se opone fuertemente al "proyecto de muerte" del agronegocio, de la agricultura sin campesinos ni familias, de monocultivos industriales, de áreas rurales sin árboles, de desiertos verdes y tierras envenenadas con agrotóxicos y transgénicos. Con nuestras acciones y prácticas las campesinas y campesinos de todo el mundo estamos activamente confrontando al capital y al agronegocio, disputando la tierra y el territorio con ellos".
} 
globalización económica, continuar movilizándose por adquirir el control de los sistemas de producción, distribución y consumo, y seguir defendiendo los territorios de los intentos del capital de expandirse en nuevos espacios geográficos. Sin embargo, comunizar, o hacer común, no solo exige la apropiación comunitaria de los modos materiales y culturales de existencia. También exige un acuerdo común de cuáles serían las herramientas técnicas que deberían utilizarse y qué otras tendrían que proscribirse; criterio que depende de la deliberación diferenciada y autónoma de qué herramientas estarían al servicio de la colectividad y bajo el poder de los pueblos, y que otras no, de modo que se evite cualquier intervención externa que amenace con generar esclavos tecnológicos y trate de perpetuar las cadenas de explotación (ILLICH y BORREMANS, 2006). Pensamos que es justamente lo que está en juego en la disputa por la despolitización de la agroecología y las intenciones de la institucionalidad por incorporarla a los lenguajes y prácticas del desarrollo.

Aunque muchos defensores de la agroecología, no logren aún desvincularse de los conceptos tóxicos del desarrollo, en latitudes como Cuba la agroecología ha venido posicionándose como una alternativa que se distancia pragmáticamente de aquellos preceptos ideológicos que han devenido como incuestionables - necesidades, participación, planificación, producción, progreso, sustentabilidad, progreso (SACHS, 1996). Creemos que es fundamental apreciar por parte de los movimientos sociales y la academia que en la práctica social ya existen experiencias que, sabiéndolo o no, están transitando hacia algo totalmente diferente de lo que promueve la institucionalidad con su discurso y práctica del desarrollo. El riesgo es que si los movimientos no hacen conciencia de ello, podrían no darse cuenta de que están siendo útiles a la cooptación de los programas y proyectos nocivos, y que están ayudando a salvar al capital de sus propias contradicciones.

Con todo lo antes dicho, no queremos sugerir que el hecho de que la agroecología esté siendo motivo de interés por la FAO y la institucionalidad del desarrollo no sea una buena oportunidad para que las demandas de los movimientos sociales sean escuchadas. Todo lo contrario: no será posible escalar la agroecología si continúa la maquinaria institucional favoreciendo el agronegocio industrial y las tecnologías de la revolución verde mediante subsidios, créditos, programas de extensión y todo el aparato de incentivos con los que se ha expandido el modelo de desarrollo rural durante los últimos cincuenta años. Lo que sí estamos asegurando es que se debe 
tener todo el cuidado de no caer en la ingenuidad de creer que al fin se han abierto las puertas para transformar la estructura agraria mundial hacia la agroecología, y que más bien los movimientos sociales deben permanecer alertas, para evitar que con los ensayos de institucionalización se creen dependencias a los programas y proyectos públicos, lo que puede generar una burocratización generadora de demagogias deshabilitantes.

Estamos en una coyuntura de la que los movimientos no pueden desentenderse. De hecho, abstenerse de hacer parte de las discusiones es dejar libre el camino para que el capital encuentre salidas a la crisis crónica sobreacumulación mediante el despojo, mientras reestructura temporalmente sus condiciones de producción. Pero ante todo, es una inmejorable ocasión para que durante el rechazo a los intentos de apropiación, se reacomoden las fuerzas, se reinventen los postulados de lucha, se actualicen las formas de resistencia, se reagrupen organizaciones dispersas, y se redefina el sentido de las alternativas, como ocurrió en el Foro Internacional de Agroecología en Nyéléni. Al final una de las mayores contradicciones del capital, es que en sus intentos de engullirlo todo; en sus afanes por insertar cada reducto espacial y humano a sus circuitos de acumulación, acaba por reforzar las luchas de los pueblos, teniendo el efecto antagónico de robustecer la movilización, al tiempo que los pueblos se reapropian de su patrimonio natural, revalorizan sus culturas, y redoblan sus esfuerzos por construir procesos sociales efectivos de territorialización de la agroecología.

\section{Referencias}

ALTIERI, M. y TOLEDO, V.M. The agroecological revolution of Latin America: rescuing nature, securing food sovereignity and empowering peasants, The Journal of Peasant Studies, v. 38, n. 3, p. 587-612. 2011.

BARTRA, A. Con los pies sobre la tierra. En: BARTRA, A. PORTO-CONCALVEZ, W. y BETANCOURT, S. Se hace terruño al andar. Las luchas en defensa del territorio. México D.F: Itaca, 2016.

BARTRA, A. Hambre y Carnaval. Dos miradas a la crisis de la modernidad, México D.F.: Universidad Autónoma Metropolitana, 2013. 
BARTRA, A. El capital en su laberinto. De la renta de la tierra a la renta de la vida, México D.F.: Editorial Itaca - Universidad Autónoma de la Ciudad de México, 2006.

BORRAS Jr, S. M., HALL, R., SCOONES, I., WHITE, B., y Wolford, W. Towards a better understanding of global land grabbing: an editorial introduction. The Journal of Peasant Studies, v. 38, n. 2, p. 209-216, 2011.

BRENNER, R. Un análisis histórico-económico clásico de la actual crisis, Revista Sin permiso Disponível em: <http://www.sinpermiso.info/textos/index.php?id=2385>. Acesso em: 1 de agosto de 2016. 2009.

BRENNER, R. El desarrollo desigual y la larga fase descendente: Las economías capitalistas avanzadas desde el boom al estancamiento, 1950-1998. Encuentro XXI. 14, 1999.

COMPOSTO, C. y NAVARRO, M.L. Claves de lectura para comprender el despojo y las luchas por los bienes comunes naturales en América Latina", En: Despojo capitalista, luchas en defensa de los bienes comunes naturales y alternativas emancipatorias para América Latina. México D.F.: Bajo Tierra Ediciones, 2014.

CROWTHER, T. W., GLICK, H. B., COVEY, K. et al. Mapping tree density at a global scale”, Nature, v. 525, n. 7568, p. 201-205, 2015.

DA SILVA, V.I. Classe camponesa: modo de ser, de viver e de produzir. Brasil: Padre Josimo, 2014.

ESCOBAR, A. Sentipensar con la tierra: nuevas lecturas sobre desarrollo, territorio y diferencia. Medellín, Ediciones Unaula, 2014.

ESCOBAR, A. La invención del tercer mundo. Construcción y deconstrucción del desarrollo, Caracas, Fundación Editorial el perro y la rana, 2007.

ESTEVA, G. Más allá del desarrollo: la buena vida. En: La agonía de un mito ¿cómo reformular el "desarrollo"? Madrid: Editorial SODePAZ, 2011.

ESTEVA, G., PRAKASH, M. S., y STUCHUL, D. L. From a pedagogy for liberation to liberation from pedagogy. Re-Thinking Freire: Globalization and the Environmental Crisis. New Jersey: Lawrence Erlbaum Associates, 2005.

ETC Group. Who will feed us? Questions for the food and climate crisis. ETC Group Communiqué, v. 102, n. 1, 2009.

FAO. Mensajes clave del Simposio de Biotecnologías Agrícolas, FAO, Roma, 2016a. 
Informe resumido del Simposio Internacional de la FAO "La función de las biotecnologías agrícolas en los sistemas alimentarios sostenibles y la nutrición” , FAO: Roma, $2016 b$.

. Final report for the International Symposium on Agroecology for Food Security and Nutrition, FAO: Roma, 2015a.

El estado mundial de la agricultura y la alimentación 2014. Roma: FAO, 2015b.

FAO y WWC. Towards a water and food secure future. Critical Perspectives for Policymakers, Roma-Masella: FAO-WWC, 2015.

FERNANDES, B. M. Questão agraria: conflictualidade e desenvolvimento territorial. En: A. M. Buainain (editor), Luta pela terra, reforma agraria e gestã de conflitos no Brasil. Campinas: Editora UNICAMP, 2008.

FOUCAULT, M. La arqueología del saber. México D.F: Siglo XXI Editores. 2010.

Los anormales. Curso en el Collége de France (1974-1975). México D.F.: Fondo de Cultura Económica, 2000.

GIRALDO, O.F. Agroextractivismo y acaparamiento de tierras en América Latina: una lectura desde la ecología política, Revista Mexicana de Sociología, v. 77, n. 4, p. 637-662, 2015.

GIRALDO, O.F. Utopías en la era de la supervivencia. Una interpretación del Buen Vivir. México D.F.: Itaca, 2014.

GIRALDO, O.F. Hacia una ontología de la Agri-Cultura en perspectiva del pensamiento ambiental, Polis Revista Latinoamericana, v. 34, p. 95-115, 2013.

HARVEY, D. El "nuevo" imperialismo: acumulación por desposesión. Socialist Register 2004: el nuevo desafío imperial, Buenos Aires: CLACSO, 2005.

. El nuevo imperialismo. Madrid: Ediciones Akal, 2004.

Espacios de esperanza. Ediciones Akal, 2003.

HOLT-GIMENEZ, E. Campesino a campesino. Voces de Latinoamérica. Movimiento Campesino a Campesino para la agricultura sustentable, Managua: SIMAS, 2008.

ILLICH, I. La convivencialidad, En: Obras Reunidas I, México D.F., Fondo de Cultura Económica, 2006. 
ILLICH, I. y BORREMANS, V. La necesidad de un techo común. En: Obras reunidas I, México: FCE. 2006.

ILLICH, I. Necesidades, En: Sachs, W. (editor), Diccionario del desarrollo. Una guía del conocimiento como poder, Pratec, Lima, 1996.

KHADSE, A., ROSSET, P.M. MORALES, H. y FERGUSON, B.G. Taking agroecology to scale: The Zero Budget Natural Farming peasant movement in Karnataka, India. The Journal of Peasant Studies (en prensa). 2016

KOTSCHI, J. A Soiled Reputation: Adverse Impacts of Mineral Fertilizers in Tropical Agriculture, Berlín: World Wildlife Fund-Heinrich Böll Stiftung, 2013.

LA VÍA CAMPESINA (LVC). Declaración de Marabá, Disponível em: $<$ https://viacampesina.org/es/index.php/acciones-y-eventos-mainmenu-26/17-de-abril-dde-la-luchacampesina-mainmenu-33/2625-conferencia-internacional-de-la-reforma-agraria-declaracion-demaraba>. Acesso: 9 de agosto de 2016. 2016

LA VÍA CAMPESINA (LVC). Declaración Foro Internacional de Agroecología, Disponível em: $<$ http://viacampesina.org/es/index.php/temas-principales-mainmenu-27/agricultura-campesinasostenible-mainmenu-42/2354-declaracion-del-foro-internacional-de-agroecologia $>$. Acesso: 5 de junio de 2015. 2015a.

LA VÍA CAMPESINA (LVC). Agroecología campesina por la soberanía alimentaria y la madre tierra. Experiencias de La Vía Campesina. Cuaderno No. 7. Zimbabwe: LVC, 2015 b.

Agricultura campesina sostenible: Por la soberanía alimentaria y la Madre Tierra. En: De Maputo a Yakarta. 5 Años de agroecología en La Vía Campesina. Jakarta: LVC, 2011.

LEFF, E. Racionalidad ambiental. La reapropiación social de la naturaleza, México D.F.: Siglo XXI Editores, 2004.

. Ecología y capital: hacia una perspectiva ambiental del desarrollo, México D.F.: Siglo XXI Editores, 1986.

LIN, B., M. JAHI CHAPPELL, J., VANDERMEER, J., SMITH, G., QUINTERO, G., BEZNERKERR, R., MCGUIRE, K. L., NIGH, R., ROCHELEAU, D., SOLURI, J., y PERFECTO, I., Effects of industrial agriculture on climate change and the mitigation potential of small-scale agroecological farms, Animal Science Reviews, v. 6, n. 20, p. 1-18, 2011.

LOH, J. Living planet report 2000. Gland: WWF--World Wide Fund for Nature, 2000. 
MACHÍN, B. ROQUE, A.M. ÁVILA, D.R. y ROSSET, P. M. Revolución agroecológica. El movimiento campesino a campesino de la ANAP en Cuba, Bogotá: Asociación Nacional de Agricultores Pequeños-La Vía Campesina, 2010.

MARTÍNEZ-TORRES, M. E., y ROSSET, P. M. Diálogo de saberes in La Vía Campesina: food sovereignty and agroecology. Journal of Peasant Studies, v. 41, n. 6, 979-997, 2014.

MARX, K. El capital. Crítica de la economía política. Tomo III. Bogotá: Fondo De Cultura Económica, 1946.

MILLENNIUM ECOSYSTEM ASSESSMENT (MEA). Ecosystems and Human Well-being: Synthesis. Washington, DC. Island Press, 2005.

NICHOLLS, C. SOCLA reflexiones sobre la Consulta Multisectorial sobre Agroecología en Asia y el Pacífico, organizada por la FAO, SOCLA, 2015.

Reflexiones sobre la participación de SOCLA en el Simposio Internacional de Agroecología para la seguridad Alimentaria y Nutrición en FAO, Roma: SOCLA, 2014.

O'CONNOR, J. R. Causas naturales: ensayos de marxismo ecológico. Siglo XXI Editores: México D.F., 2001.

PINGALI, P. L., HOSSAIN, M., y GERPACIO, R. V. Asian rice bowls: the returning crisis?. Manila: International Rice Research Institute, 1997.

POLANYI, K. La gran transformación: los orígenes políticos y económicos de nuestro tiempo, México D.F.: Fondo de Cultura Económica, 2003.

PORTO GONÇALVES, C. W. O Latifúndio Genético e a R-existência Indígeno-Camponesa. Geographia, v. 4, n. 8, p. 30-44, 2009.

RAY, D. K., RAMANKUTTY, N., MUELlER, N. D., WEST, P. C., y FOLEY, J. A. Recent patterns of crop yield growth and stagnation, Nature communications, 3, 1293, 2012.

ROGÉ, P. NICHOLLS, C. y ALTIERI, M.A. Reflexiones sobre la reunión regional de la FAO sobre Agroecología para África subsahariana, SOCLA, 2015.

ROSSET, P. Re-thinking agrarian reform, land and territory in La Via Campesina. Journal of Peasant Studies, v. 40, n. 4, 721-775, 2013.

ROSSET, P.M. La Guerra por la tierra y el territorio. En: Primer Coloquio Internacional In Memoriam Andrés Aubry: planeta tierra: movimientos antisistémicos. San Cristóbal de las Casas: Cideci-Unitierra Ediciones, 2009. 
ROSSET, P. M., y MARTÍNEZ-TORRES, M. E. Agroecología, territorio, recampesinización y movimientos sociales. Estudios Sociales, v. 25, n. 47, p. 275-299, 2016.

ROSSET, P. M., y MARTÍNEZ-TORRES, M. E. Rural social movements and agroecology: context, theory, and process. Ecology and society, v. 17, n. 3, p. 17, 2012.

ROSSET, P. M., MACHÍN SOSA, B., ROQUE JAIME, A. M., y ÁVILA LOZANO, D. R. The Campesino-to-Campesino agroecology movement of ANAP in Cuba: social process methodology in the construction of sustainable peasant agriculture and food sovereignty. The Journal of peasant studies, v. 38, n. 1, 161-191, 2011.

SACHS, W. Diccionario del desarrollo. Una guía del conocimiento como poder, Pratec: Lima, 1996.

VÁSQUEZ, J.I y RIVAS, A. De campesino a campesino. Managua: Unión Nacional de Agricultores y Ganaderos, 2006.

WEZEL, A., BELLON, S., DORÉ, T., FRANCIS, C., VALLOD, D., y DAVID, C. Agroecology as a science, a movement and a practice. A review. Agronomy for sustainable development, v. 29, n. 4, p. 503-515, 2009.

Artigo recebido em 10/08/2016. Autores convidados. 